\title{
Towards Hospital Marketing at the Brazzaville University Hospital Center
}

\author{
Moyo Nzololo \\ Faculty of Economic Science, Marien NGOUABI University, ESGAE, Brazzaville, Congo \\ Email: emmalo2@yahoo.fr
}

How to cite this paper: Nzololo, M. (2020). Towards Hospital Marketing at the Brazzaville University Hospital Center. Open Journal of Business and Management, 8, 24092422.

https://doi.org/10.4236/ojbm.2020.86149

Received: September 15, 2020

Accepted: November 7, 2020

Published: November 10, 2020

Copyright (c) 2020 by author(s) and Scientific Research Publishing Inc. This work is licensed under the Creative Commons Attribution International License (CC BY 4.0).

http://creativecommons.org/licenses/by/4.0/

\section{(c) (i) Open Access}

\begin{abstract}
The theoretical framework of this article is service marketing. It endeavors to show that the hospital restructuring of the Brazzaville University Hospital Center (CHUB) has the major objective of significantly reducing the hospital mortality rate at the CHUB to around 10\%. To achieve this, in 2019 the Congolese government signed a governance contract with the International Health Unit of the Centre hospitalier universitaire de Montréal to ensure that in three years, 2019-2022, the CHUB will regain its attractiveness to patients. The new governance, based on hospital marketing, encountered obstacles related to change during year 1 of its implementation. The article deals with the level of implementation of hospital marketing within the CHUB based on five hypotheses and considers conditions for success by 2022 .
\end{abstract}

\section{Keywords}

Hospital Marketing, University Hospital Center, Service Marketing, Hospital Mortality Rate, Brazzaville

\section{Introduction}

The announcement of the arrest of two doctors, following the death of a patient on May 29, 2020, who was to undergo a caesarean section, was the first case in the history of Congo Brazzaville. The lady went successively to three health facilities in Brazzaville - Makélékélé hospital where she took three days, then to the Blanche Gomès mother and child hospital where, due to lack of oxygen, she was transferred to a covid center, as she was suspected to be a positive case, the Albert Leyono clinic where she died after testing negative. It is evident that the patient's journey was strewn with multiple negligent care in these different health facilities. Risk management should be a concern of the leaders in charge of health care institutions and organizations (Zolla, 2017; Louazel et al., 2018). 
This drama, which took place in the middle of the covid-19 period, has brought up on the media scene questions related to the quality of patient care by the health system in Congo, Brazzaville. This led to threats to health personnel from the family and to the protection of the doctors concerned by the police. This is what Dargachi \& Hafsia Lallouna (2017) describe as deviant user behavior.

The health situation in the Congo is worrisome as indicated by the priority problems identified in the 2018 Health Sector Review Report and the mortality reduction objectives presented in the National Health Development Plan 2018-2022.

We chose to use the Brazzaville University Hospital Center (CHUB) as the framework for our investigation, because it is located at the top of the pyramid of the health system in Congo, Brazzaville. It is the health establishment of reference. The CHUB was created by law no. 008/87 of February 7, 1987. It is a social and administrative establishment with a legal personality and financial autonomy. The university character is based on an agreement signed on July 7 , 1988 between the CHUB and the Faculty of Health Sciences of Marien Ngouabi University. Inaugurated in February 1989, the CHUB has three essential missions: the provision of quality care, the training of medical staff and biomedical research.

Our interest in this field of investigation is that, following a financial and systems audit for the fiscal years 2013 to 2015 funded by the Ministry of Health and Population on the one hand, and an audit of CHUB governance practices from October 2016 to May 2017 funded by the World Health Organization (WHO) on the other hand, two main points emerge (Kane, 2019: p. 2). The situation of the Brazzaville University Hospital Center (CHUB) deserves urgent and vigorous action on the part of the Congolese political authorities, the Ministry of Health and Population and the managers of the CHUB itself; the buildings, processes, care environment and quality do not meet international standards.

Quality has disappeared at the CHUB in terms of: care and service provision, the care environment, care safety and the organization of care. However, the medium-term vision of the directors of this public healthcare establishment is to make the CHUB "a university-level hospital that meets international standards, offering care and services of a high level of specialization centered on the user, well organized, equipped with efficient governance and management tools and structures, and managed with transparency and accountability for results" (CHUB, October 2019: p. 4).

This vision reflects a strong desire on the part of the CHUB's managers to differentiate themselves by the offer or its terms and conditions on the territory and to focus on activities that other healthcare institutions or competitors do not invest in.

To this end, the Government has taken its responsibilities in:

- In January 2019, Sylvain Villiard, a Canadian, was appointed Executive Director of the CHUB; 
- Signing in April 2019, for a period of three years, a service provision contract between the CHUB and the UCC consortium (Unité de santé internationale de l'Université de Montréal (USI)/Centre hospitalier de l'Université de Montréal (CHUM)/Centre hospitalier universitaire Ibn Sina de Rabat (CHUIS)).

The appointment of the CEO underlines that the management of marketing at the hospital has a strategic dimension that is the responsibility of the general management, hence the importance of a new governance structure.

The "CHU" rhymes with the "CHtue". Every patient is afraid to go to the CHUB because it is most likely to die there. Such is the perception of the Congolese population with regard to their health establishment of reference.

Objectives

The main objective of this article is to show that the hospital restructuring of the CHUB based on the implementation of hospital marketing can contribute to the attractiveness of the CHUB to patients.

Two specific objectives are associated with this main objective:

- Reconquering the trust of customers because it is the foundation of customer loyalty and contributes to having a good reputation;

- Improve the image of the CHUB.

Problem

The in-hospital mortality rate in the $\mathrm{CHU}$ is around $10 \%$, compared to $3 \%$ by international standards (CHUB, October 2019: p. 20). This very significant difference does not allow the CHUB to be attractive to patients.

Hospital marketing at the CHUB is justified for four reasons:

- an approach adapted to the CHUB's situation as a company in difficulty in a competitive healthcare market with its own characteristics and to guarantee sufficient activity to ensure its financial sustainability and the necessary investments;

- a useful approach in the face of change and progress, which requires that the attractiveness of the CHUB become a vital concern on the one hand, and that the patient be at the heart of this approach on the other;

- an approach contributing to the CHUB's strategic vision through its strategic plan;

- an approach that benefits the company and creates a dynamic involving all the hospital's healthcare staff around a common project.

Thus, hospital marketing can be defined as a set of approaches aimed at supporting the attractiveness of a hospital through effective internal and external communication and a constant search for patient satisfaction through a quality relationship (Lebailly, 2018).

In the context of hospital marketing, the marketing offer that is characterized by the 4 Ps (Amstrong \& Kotler, 2020) translates into the 4Ps of hospital marketing as follows:

- The Product corresponds to the global offer of the health establishment 
through a product catalog. The "good" hospital product, in marketing terms, is the one that satisfies both the patient and the doctor or the structure that sent the patient.

- The Price is not a variable of the marketing action in the hospital because it is set in order to welcome the largest number of patients. However, it is the ancillary services related to the attractiveness of the hospital that will make the difference in the price.

- La Place concerns both the location of the hospital, i.e. its accessibility and its capacity, the reception conditions and the technological developments contributing to the quality of care, patient safety and patient management.

- The Promotion mainly concerns the hospital's external communication within the framework of "B to B", i.e. towards health professionals and "B to C" towards the general public.

As Bouglon (2020) points out: "Hospital marketing is a new challenge for hospitals".

According to Kotler and Clarke cited by Crié et al. (2015): "Hospital marketing is a marketing orientation of the hospital according to five criteria: 1) a 'customer' philosophy; 2) integrated marketing; 3 ) a marketing information system; 4) a strategic orientation; 5) operational efficiency".

Our research question is the following: is the CHUB involved in the hospital marketing process? According to Kotler and Clarke, this means asking the following five sub-questions in relation to the five criteria above:

Q1: Are the needs and expectations of "customers" considered in the development of the organization's strategy and activities?

Q2: Does the organization conduct marketing analysis, planning, implementation and monitoring of marketing activities?

We can rephrase this question into two sub-questions:

Q2.1: Does the organization conduct planning?

Q2.2: Does the organization conduct marketing analysis, implementation and monitoring of marketing activities?

Q3: Does management have the necessary and quality information to conduct effective marketing policies?

Q4: Does the organization implement strategies and planning for the achievement of its long-term goals?

Q5: Are the marketing activities deployed effective?

With respect to each of these issues that relate to the five criteria, we have made five assumptions.

H1: The CHUB has a "customer" philosophy. H2: Integrated marketing is partial at the CHUB. H2.1 The CHUB has a planning plan

H2.2: The CHUB does not conduct marketing analyses or implement and control marketing activities.

H3: The marketing system is insufficient at the CHUB.

H4: The CHUB has a hospital project (PEH) 2019-2022 defining strategic 
axes.

H5: The CHUB has a prioritized medical project which is the operational translation of the PEH.

These five hypotheses are related because they characterize hospital marketing.

The service offer based on care production is patient-oriented or patient-centered (H1). Integrated marketing takes into account, on the one hand, all of the hospital's healthcare professionals involved in the production of the care service - planning for this personnel is necessary $(\mathrm{H} 2.1)$ and, on the other hand, the need for the hospital to know its external as well as its internal environment through market research and data analysis (H2.2). The H3 hypothesis allows to apprehend the attractiveness of the hospital because it uses opinion and satisfaction surveys. Hospital marketing has a strategic dimension that is the responsibility of general management, which is reflected in hypothesis $\mathrm{H} 4$; hypothesis $\mathrm{H} 5$ is the operational translation of this strategic vision.

This article is divided into three parts: literature review, material and method, and finally results and discussion.

\section{Literature Review}

Hospital marketing belongs to the two major marketing families, "B to B" and " $B$ to $C$ ", where " $B$ " is an institution or healthcare professional and " $C$ " is the patient (Huet \& De Renaudie, 2020).

Since a hospital's environment is competitive, a marketing mindset deserves to be developed as a service company (Ponchon, 2018; Houver, 2020).

Minvielle and Durand (2016) show that hospital managerial innovations are based on four dimensions: organizational strategy and processes, organizational change intervention methods, team management and service to patients and their families.

Holcman (2019) emphasizes the importance of hospital management by mastering the rules of management in a healthcare establishment, whether public or private.

The hospital does not aim for the profitability and profit pursued by a commercial enterprise; however, it must make the best possible use of the resources made available to it. Thus, Aubert (2009: p. 8) defines hospital marketing as: "the development of an offer of adapted, differentiated and quality services in the broadest sense, so as to ensure the public service mission of caring for the population of its territory at the best cost for it and the community".

Nimi et al. (2020) indicate the obstacles in the hospital environment encountered during hospital reform: difficulties related to public services, production of services whose processes are not always standardized, organizational and social obstacles, managerial obstacles and technical obstacles.

Crié et al. (2015) distinguish three categories of attitude towards the marketing approach in hospitals: rejection of marketing, why not? and acceptance of 
marketing. For those in the third category, hospital marketing makes it possible to: support the hospital's strategy (strategic project, strategic image or positioning, strategic orientation, care and service offer strategy, recruitment strategy, etc.), face competition from the private sector, organize external and internal communication, use tools for analyzing patient satisfaction.

Langeard and Eiglier (1999) explain that the service relationship is at the heart of service marketing because it concretizes the exchange or direct contact between the company and its customer. In service marketing, this relationship is global because "the management of this relationship integrates the role of the customer as co-producer of the service". The signs that accompany the service relationship are very diverse and reflect the way in which the service has been appreciated by the customer: positively or negatively. Therefore, the service relationship cannot be improvised. It conditions the implementation of the service offer.

The service strategy is based on the service formula comprising the following three elements: the customer, the service offer and the support of the service formula (Chambaretaud, 2003).

There is a great similarity between the supply of services and the supply of care. Hospital marketing can therefore be assimilated to the service marketing model. However, the services provided in hospitals are intangible, immaterial and are consumed as they occur. They involve contact between the client and the producer (Lebailly, 2018).

Kotler et al. (2019) have indicated that service marketing includes three types of marketing:

"External marketing describes the classic work of targeting, positioning, branding, service design, pricing, distribution and communication;

- Internal marketing, means that the company must train and motivate all its staff to serve its customers well;

- Interactive marketing emphasizes that perceived quality is closely linked to the customer/seller interaction. The customer judges not only the technical quality of the service (was the surgery successful?), but also its functional quality (did the surgeon inspire confidence?). Teamwork plays an essential role. By delegating authority to the staff in contact with the client, we develop the flexibility of the service in order to better solve problems, to involve employees more and to promote the transfer of knowledge".

\section{Material and Method}

\subsection{Material}

The data for this article comes from the following documents:

- The National Health Policy 2018-2030;

- The national health development plan 2018-2022;

- The 2018 Health Sector Review Report;

- The national health map 2015; 
- The financial audits and summary of the CHUB financial years 2013 to 2015 commissioned by the Ministry of Health and Population;

- The practical audit of governance at CHUB commissioned and funded by the World Health Organization (WHO) in 2016;

- The audit of practices at the CHUB-governance, quality of management, degree of transparency, organization and financial capacity-in 2016;

- The service provision contract signed by the Government and between the CHUB on the one hand, and the UCC consortium on the other, in 2019.

\subsection{Method}

Our method consisted of three steps:

1) To highlight the main weaknesses that makes the CHUB a "big general hospital";

2) Identify the service strategy for the restructuring of the CHUB;

3) Analyze to what extent this service strategy, which is part of the general framework of service marketing, leads the CHUB towards hospital marketing.

\section{Results and Discussion}

The results and discussion are presented based on the five assumptions we have made.

\subsection{The CHUB Has a "Customer" Philosophy}

The customer is the first strategic lever of the service formula. The relationship between the customer and the service provider (the healthcare staff) must be a "relationship of trust" aimed at customer satisfaction but also customer loyalty. Customer dissatisfaction must be taken into account and not trivialized or ignored. Makany $(2005,2007)$ sounded the alarm by reporting that in Congolese public opinion "CHU” rhymes with "CHtue" because of the persistent deterioration in the quality of life in this health infrastructure. Fourteen years later, the situation has not changed, as Kane (2019: p. 2) points out: The audit of practices carried out at the CHUB showed that, contrary to expectations, this health establishment is "a large general hospital" offering poor quality care, with few quality diagnostic services and a training vocation.

Having taken office on April 16, 2019, the CHUB's new Executive Director, Sylvain Villiard, a Canadian, stated the CHUB's “customer" philosophy in the following terms: "The patient at the heart of our concerns".

“This constant concern for the patient's well-being must be integrated into all of our agents' daily actions and into our management systems supporting the care episode" (CHUB, September 2019).

In other words, the values, standards and actions of each member of the CHUB must be oriented towards service and customer satisfaction.

In order to regain the client's trust, the "client" philosophy is based on values 
in terms of ethics and professional ethics that determine the actions of the CHUB management and its staff (Table 1). It is easy to understand that the absence of these values has largely contributed to increasing client mistrust of the CHUB over the years.

Hypothesis $\mathrm{H} 1$ is validated because there is a "customer" philosophy at the CHUB and a system of values, including "customer-oriented" or "customer service-oriented" values.

\subsection{Integrated Marketing Is Partial}

\subsubsection{The CHUB Has a Planning Plan}

Formula service support is the place of the interface with the customer. What happens at the interface is the succession of several moments of truth in this path, from the customer to the service provider, a path that we call the customer path. "At each stage, the service gains or loses its chance to be perceived positively or negatively by the customer" (Chambaretaud, 2003: p. 114).

The support of the service formula therefore implies the management capacity of the customer but also of other customers and sometimes of a crowd. The service staff therefore has both a relational and expertise obligation. And one could imagine managerial and technological innovations for more efficiency at the interface. Hence the importance of well-trained staff. Among other things, this includes continuing professional training for CHUB agents in several forms: adaptation training, refresher training, knowledge maintenance, updating of knowledge, complementary training, evolution training, conversion or reconversion training and training seeking preventive management through skills. This contributes to attracting, integrating and retaining employees (Ligier, 2016).

A diploma verification operation undertaken by the general management of the CHUB in January 2020 revealed 250 agents (doctors, nurses and administrative staff) holding false diplomas ${ }^{1}$. In addition, 120 fictitious employees and deserters were detected and around sixty of them were struck off the payroll ${ }^{2}$.

The various audits mentioned above have highlighted the following two points with regard to resource management procedures:

- The CHUB does not have appropriate procedures and standards for recruitment, evaluation and promotion (particularly for employees in administrative functions);

- There is no training and career plan. Some training is carried out at the request of agents" (CACOGES, 2017).

As a result, workforce planning has been put in place for the year 2020 (Table 2).

${ }^{1} 250$ agents (médecins et infirmiers) ont des faux diplômes, 120 salariés sont fictifs. (Accessed June 12, 2020) https://sacer-infos.com/chu-b-250-agents-medecins-et-infirmiers-ont-de-faux-diplomes-120-sont-fi ctifs

${ }^{2}$ Une soixantaine d'agents radiés au CHU de Brazzaville. (Accessed June 12, 2020)

https://www.voaafrique.com/a/une-soixantaine-d-agents-radiés-du-chu-de-brazzaville/5265311.htlm 
Table 1. Excerpt from patient-oriented CHUB values.

- Staff development and recognition of their expertise to meet the needs of patients;

- Prohibition of receiving direct or indirect monetary benefits from patients in the performance of his or her duties;

- The exercise of an adequate work in quantity and quality;

- The respect of the confidentiality of the information gathered in the course of their work as well as the code of ethics of their profession;

- Behaviour characterized by empathy, courtesy, friendliness and respect for patients, other agents and superiors;

- The use of drugs, consumables and other equipment exclusively for the provision of care and services to CHUB patients;

- Respect and make respect the quietness, calm and rest of the patients.

Source: CHUB, September, 2019.

Table 2. Workforce planning.

Workforce planning (PMO) is a set of activities to assess the demand and supply of labour. It allows the institution to assess human resource needs quantitatively and qualitatively over the short, medium and long term. It is usually linked to the budget process and focuses mainly on vacancies, hiring forecasts and internal needs projections.

A first PMO exercise will be carried out at the CHUB during the year 2020 and will have to be updated once a year starting the first week of October each year by the Director of Human Resources (DHR). The results of this process will feed into the decision-making process for internal or external recruitment.

Source: CHUB, September 2019.

The PMO will be based on the hiring guide now available to the CHUB adopted on October 9, 2019 during the 24th ordinary session of the Management Committee (CHUB, September 2019). Commenting on the new guide, Ulrich Judicaël Biez, Deputy General Manager, said: “This is the first time that our structure will have a hiring guide that defines the hiring procedures and these procedures are transparent, objective and fair. This guide will enable us to avoid continuing with recruitment based on subjective criteria that do not guarantee us quality health personnel" (Koussoukama, 2019).

PMO fits well within the framework of integrated marketing insofar as it contributes to improving the quality of care and better patient management at the various stages of the patient's journey; it thus contributes to patient satisfaction. In addition, the PMO and the hiring guide are also motivational tools that are part of internal marketing. Thus, as Langeard and Eiglier (1999) point out: The quality of the service relationship has its roots deep within the organization. There can be no watertight barrier between functions such as marketing and human resources.

\subsubsection{The CHUB Does Not Carry out Marketing Analyses or the Implementation and Control of Marketing Activities}

The team in charge of developing the CHUB's prioritized medical project states in its report: "It was not possible to obtain sufficient data to carry out a complete analysis of the supply of care and services in the territory where the CHUB is located: health demand, user profile, competition and market share, medical and 
paramedical demographics, etc.”. (CHUB, October 2019, p. 12). The CHUB does not conduct market research. It is obvious that the absence of such data cannot allow the CHUB to conduct marketing analyses or the implementation and control of marketing activities. This is in line with the general observation of the Ministry of Health and Population (MSP): "Congo does not have a strategic plan for the development of the national health information system. Data quality remains a major concern" (MSP, 2018: p. 58).

The CHUB is located in a competitive environment made up of 773 public and 872 private healthcare institutions (MSP, 2015). The lack of market research at the CHUB could be explained by its positioning at the top of the healthcare pyramid, which gives it the illusion of being, as a result, the best healthcare establishment. However, one can also deplore the absence in the Congolese press of the publication of a ranking of health care institutions, as published in the French newspaper Le Point (2001). In general, however, public health facilities are reluctant to conduct market studies to better understand the competition and often rely on government funding. Quality in hospitals has a price. Government subsidy cannot solve everything. Private health care institutions differ from the CHUB in terms of the quality of their reception, waiting times and the quality of the care environment. These private health care institutions strive to maintain the image of a service company as perceived by the customer. This image comes from the technical and functional quality of the service (Boyer \& Nefzi, 2009).

The $\mathrm{H} 2$ hypothesis is thus partially validated, because only $\mathrm{H} 2.1$ is validated.

\subsection{The Marketing Information System Is Insufficient}

A marketing information system (MIS) has three components (Kotler et al., 2019: p. 89):

- "A marketing intelligence system, corresponding to all the means that allow managers to keep themselves continuously informed about the evolution of their marketing environment: demographic, economic, socio-cultural, natural, technological, regulatory;

- A system of market studies made punctually;

- An internal information system composed of the order-delivery-billing cycle, sales statements and databases".

As for the marketing intelligence system, it is found in the National Health Policy (PNS), the National Health Development Plan (PNDS) 2018-2022 and the National Health Map developed by the Ministry of Health and Population.

A system of market research conducted on an ad hoc basis could consist of opinion and satisfaction surveys. This is not done at the CHUB.

As far as the internal information system is concerned, it does exist at the CHUB. In the organization chart, it is part of the Statistics, Studies and Planning Department attached to the Management Control Department. However, the CHUB's financial and system audits have indicated several weaknesses in the 
CHUB's internal information system (CACOGES, 2017).

Nimi et al. (2020: p. 167) observes that: "the problems of hospital information systems (HIS) represent obstacles to the production of hospital information characterized by reliability, exhaustiveness and sharing". This lack of reliable information leads to inefficient decisions.

As one out of three SIM components exist at the CHU, we conclude that the marketing information system is insufficient at the CHUB.

\subsection{The CHUB Has a Hospital Establishment Project (PEH) 2019-2022 Defining Strategic Axes}

The CHUB's Hospital Establishment Project $(\mathrm{PEH})$ was adopted by the Steering Committee in its session of October 12, 2018. "The PEH lays the foundations for a new organization centered on hospital activities and an optimized and better structured patient pathway. It is a healthcare and health services organization scheme, developed with a view to a secure and quality healthcare and healthcare services offer" (CHUB, October 2019: p. 26).

The CHUB's strategy is to become a healthcare establishment capable of adapting to the constant changes that characterize the healthcare field, both in terms of the evolution of patient care methods and the development of medical techniques.

The 5 strategic axes of the PEH are: medical project, nursing care, logistics, training and governance support project.

For the implementation of the HEP, a service provision contract between the CHUB and the UCC consortium (Unité de santé internationale de l'Université de Montréal (USI)/Centre hospitalier de l'Université de Montréal (CHUM)/Centre hospitalier universitaire Ibn Sina de Rabat (CHUIS)) and signed with the Congolese State. The total cost of the PEH over three years 2019 to 2022 is $16,763,740,800 \mathrm{CFA}$ or $25,554,483$ euros ( 1 euro $=656$ FCFA) of which $4,763,740,800$ CFA or 7,261,800 euros are financed by the Congolese State and the rest by the Development Bank of Central African States (BDEAC). As De Pouvourville and Tedesco (2003: p. 207) point out: "The project, if it is approved by the State, guarantees that the institution will receive the level of financing required to carry out the chosen orientations".

As the CHUB has strategic axes and a $\mathrm{PEH}$, the $\mathrm{H} 4$ hypothesis is validated.

\subsection{The CHUB Has a Prioritized Medical Project Which Is the Operational Translation of the $\mathrm{PEH}$}

The Prioritized Medical Project (PMP) is a continuation of the PEH as it is the tactical or operational translation of the $\mathrm{PEH}$. The PMP targets only the priorities for action for the period 2019-2022. It is organized into 7 main lines of priority actions (Table 3 ).

The seven main lines of priority actions (LAP) are mainly oriented towards patient-client satisfaction by targeting three priority pathologies (op.cit. p. 31): 
Table 3. Seven main lines of PMP priority actions.

1) To develop medical centers of excellence, reinforcing the CHUB's mission as a pivotal institution within the healthcare system;

2) To provide the person with safe, quality care at all stages of his or her care;

3) Optimize patient management at the different stages of the patient's journey;

4) To develop ambulatory medical-surgical care;

5) Modernize the technical platform and the medico-technical services, in particular the pharmacy, laboratories and imaging, including maintenance;

6) Strengthen the CHUB's training and research capacities;

7) Implementation of a hospital information system.

Source: CHUB, October 2019.

- "Secondary and tertiary care conditions;

- Pathologies for which there are no other alternatives in the department of Brazzaville and more broadly in the country and for which treatment is problematic;

- Pathologies that cannot be treated in hospital due to a lack of technology and which are subject to evacuation".

Each of the LAPs corresponds to a "marketing" activity sheet, in the sense that these activities are aimed in particular at satisfying patient-clients through the quality of the care and services offered and improving the image of the CHUB. The two approaches that define quality of service are therefore the same. "From the customer's point of view, the term quality represents the gap between perceived benefits and expectations. From the provider's point of view, quality refers to the physical and technical specifications of the service" (Boyer \& Nefzi, 2009: p. 46).

We can consider that the PMP across the seven large LAPs allows us to validate the $\mathrm{H} 5$ hypothesis.

\section{Conclusion}

The hospital restructuring of the CHUB is underway through the implementation of the Hospital Establishment Project (PEH) 2019-2022 and in particular the Prioritized Medical Project (PMP) 2019-2022 which is the operational translation of the PEH. The seven priority action lines of the PMP are aimed at satisfying patient-customers through the quality of care and services and improving the image of the CHUB, an image tarnished by multiple negligences at all levels of the patient-customer journey. In order to improve its image, the CHUB must therefore introduce sustainable feedback procedures (REX) to learn from the daily analysis of adverse events associated with care (AEIAs) that occur during patient care. One such REX approach is the Mortality and Morbidity Review (MMR), which targets the occurrence of a death as an AEHI (Bally \& Chevalier, 2014). The CHUB management has begun a forced march towards hospital marketing, because it has encountered resistance to change on the part of a group of doctors and managers but also from the CHUB's inter-union for arbi- 
trary reasons ${ }^{3}$. The Government and the CHUB management stood against trade union to face resistance to change. And consequently, the implementation process of hospital marketing is continuing with determination. Of the five hypotheses, three are fully validated and two are partially validated. The mortgages that are partially validated depend on the CHUB's organizational chart, because there is no marketing department. In addition, the contractual financial commitments (the annual balancing subsidy and the assumption of the supplier debt) of the government deserve to be respected and there is the need to establish a permanent dialogue to calm the social climate within the CHUB. In addition, there are non-contractual conditions concerning the strengthening of the leadership of Congolese managers, the mobilization of the medical corps and the management of the rehabilitation project.

\section{Conflicts of Interest}

The author declares no conflicts of interest regarding the publication of this paper.

\section{References}

Amstrong, G., \& Kotler, P. (2020). Principes de marketing. France: Pearson.

Aubert, S. (2009). De l'opportunité d'une démarche marketing à l'hôpital. Mémoire, Paris: Ecole des Hautes Etudes en Santé Publique.

Bally, B., \& Chevalier, P. (2014). Retour d'expérience en santé (REX): Comprendre et mettre en œuvre (pp. 1-4). Mission Sécurité du patient.

Bouglon, V. (2020). Le marketing hospitalier: Nouvel enjeu pour les hôpitaux? https://voiretpenser.hypotheses.org/927

Boyer, A., \& Nefzi, A. (2009). La perception de la qualité dans le domaine des services: Vers une clarification des concepts. Revue des Sciences de Gestion, Direction et Gestion Marketing, 237-238, 43-54. https://doi.org/10.1051/larsg/2009028

CACOGES (2017). Audit financier et de synthèse du centre hospitalier universitaire de Brazzaville (CHUB). Exercices 2013, 2014, 2015

Chambaretaud, D. (2003). Construire une stratégie de service. Paris: Editions Dunod.

CHUB (2019). Guide du recrutement. Centre hospitalier Universitaire de Brazzaville. Septembre.

CHUB (2019). Projet médical priorisé $d u$. Centre hospitalier Universitaire de Brazzaville. Octobre.

Crié, D., Salerno, D., \& Vincent, A. (2015). Vers un marketing hospitalier? Problèmes économiques, 3113, 47-58.

Dargachi, S., \& Hafsia Lallouna, H. B. (2017). Effet d'une mauvaise qualité de service sur le comportement déviant des usagers: Le cas du secteur hospitalier. La Revue des Sciences de Gestion, 287-288, 99-105. https://doi.org/10.3917/rsg.287.0099

${ }^{3}$ Le collectif des médecins et cadres du Centre hospitalier universitaire de Brazzaville (CHU-B) ont exprimé leur mécontentement à l'égard de leur direction générale. (Accessed June 12, 2020) https://www.journaldebrazza.com/chu-b-lecollectif-des-agents-et-lintersyndicale-veulent-un-nouvea $\underline{\mathrm{u} \text {-directeur-general }}$ 
De Pouvourville, G., \& Tedesco, J. (2003). La contractualisation interne dans les établissements hospitaliers publics. Revue française de gestion, 146, 205-218. https://doi.org/10.3166/rfg.146.205-218

Holcman, R. (2019). Management hospitalier. Paris: Editions Dunod.

Houver, N. (2020). Le petit marketing 2020. Paris: Editions Dunod.

Huet, J. M., \& De Renaudie, F. L. (2020). Une nouvelle ère du marketing? L'impact des nouveaux business models. France: Pearson.

Kane, C. (2019). Mandat d'appui à la gouvernance du CHUB Rapport final. USI/CHUM/Université de Montréal.

Kotler, P., Keller, K. L., Manceau, D., \& Hemonnet, A. (2019). Marketing Management. Paris: Nouveaux Horizons.

Koussoukama, P. A. (2019). Le CHU-B dispose désormais d'un guide d'embauche. https://www.vox.cg/2019/10/le-chu-b-dispose-desormais-dun-guide-dembauche

Langeard, E., \& Eiglier, P. (1999). Ch. 5: Relations de service et marketing. In Marketing des services (sous la direction de Lovelock et Lapert) (pp. 151-160). Paris: Publi Union Editions.

Le Point (2001). Hôpitaux. Le Palmarès 2001, no. 1151.

Lebailly, G. (2018). Petit traité de marketing hospitalier à l'intention des infirmiers chefs d'unité. Mémoire, Tournai: Ecole d'enseignement et de promotion sociale de la communauté française.

Ligier, P. (2016). Marketing RH. Comment devenir un employeur attractif. Paris: Editions Dunod. https://doi.org/10.3917/dunod.liger.2016.01

Louazel, M. et al. (2018). Le management en santé. Gestion et conduite des organisations de santé. Paris: Presses de l'EHESP. https://doi.org/10.3917/ehesp.louaz.2018.01

Makany, R. A. (2005). Analyse statistique de la survie du centre hospitalier et universitaire de Brazzaville (CHUB) de 1993 à 2002. Cahier no 33/2002 Caen Innovation Marché Entreprise-IAE-Université de Caen Basse Normandie (19 p.).

Makany, R. A. (2007). Analyse statistique du CHUB "Centre hospitalier universitaire de Brazzaville”. Paris: Editions ICES.

Minvielle, E., \& Durand, V. (2016). Ala découverte des innovations managériales hospitalières. Paris: Presses de l'EHESP.

MSP [Ministère de la santé et de la population] (2015). Carte sanitaire nationale. Brazzaville.

MSP [Ministère de la santé et de la population] (2018). Rapport de la revue du secteur de la santé. Brazzaville.

Nimi, I. et al. (2020). Implémentation du système de contrôle de gestion au sein des hôpitaux publics marocains: Etat de l'art, avantages et contraintes. Revue du contrôle, de la comptabilité et de l'audit, 4, 156-172.

Ponchon, F. (2018). L'usager et le monde hospitalier. Paris: Presses de l'EHESP.

Zolla, E. (2017). La gestion des risques dans les établissements et services sociaux et médico-sociaux. Paris: Editions Dunod. https://doi.org/10.3917/dunod.zolla.2017.01 